\title{
Perceived Quality Improvements Using Daily Allocation of Surgical Residents to the Operating Room and Outpatient Clinics
}

\author{
Keith Wirth, ${ }^{1}$ Patricia Leung, ${ }^{2}$ Prasanth Patcha, ${ }^{2}$ and Aliu Sanni ${ }^{2}$ \\ ${ }^{1}$ SUNY Downstate Medical Center, College of Medicine, 450 Clarkson Avenue, Brooklyn, NY 11203, USA \\ ${ }^{2}$ SUNY Downstate Medical Center, Department of Surgery, 450 Clarkson Avenue, Brooklyn, NY 11203, USA \\ Correspondence should be addressed to Keith Wirth; wirthk@gmail.com
}

Received 23 May 2013; Accepted 9 September 2013

Academic Editor: Geoffrey Lighthall

Copyright (C) 2013 Keith Wirth et al. This is an open access article distributed under the Creative Commons Attribution License, which permits unrestricted use, distribution, and reproduction in any medium, provided the original work is properly cited.

\begin{abstract}
Introduction. Balancing efficiency and quality in resident education and clinical care is challenging, particularly in a large tertiary center with resident work hour restrictions. This study investigates the use of daily allocation of surgical residents to operative cases and clinics with the goal of improving patient care, resident education, and coverage. Methods. Surgical residents were allocated to cases and clinic activities a day ahead, with a central email generated and sent to all surgical staff the day prior to the procedures and duties. A ten-item questionnaire was administered to the staff on the surgery service before and after this intervention, evaluating perceptions of educational experience, patient care, and coverage of operative cases, clinic, and floor duty. Results. A total of 28 staff members participated. No significant difference was found in the perception of stress at work, coverage of OR cases, or clinic attendance after the intervention. However, a statistically significant increase $(p<0.05)$ was noted in the perception of resident's educational experience in the clinic (39\% vs. $94 \%$ ), appropriate case distribution ( $54 \%$ vs. $94 \%$ ), and quality of patient care (50\% vs. $100 \%)$. Conclusions. Daily allocation of surgical residents to operative cases and clinic activities improves perceptions of resident educational experience and quality of patient care in a busy clinical setting.
\end{abstract}

\section{Introduction}

First implemented by Halstead in 1889, the formal surgical residency model revolutionized the training of young surgeons. An important feature of this model was a clear distribution of responsibilities and clinical duties among successive training years, ensuring that students had adequate experience and decision making capacities upon their completion of the training [1]. Over the past century, this model has been refined and standardized across the country, expanding upon the principles of Halstead. However, recent changes in resident work hour regulations, in 2003 limiting hours to 80 per week and in 2011 limiting intern shifts to no more than 16 hours, have sparked controversy over the quality of patient care and resident education within the current residency model [2].

In response to the perceived or realized problems of duty hour reform, program directors have employed a number of strategies to confront these new problems, with varying success. These strategies have included leadership/communication training, increasing access to technology, hiring of fellows and midlevel providers, increasing the number of residents in each year, and changes in scheduling $[3,4]$. The changes in scheduling have focused on actual distribution of hours, such as utilizing a night float schedule, cross-coverage, and even computer algorithms to manage the complexities of scheduling [4-7].

Rather than focusing on the quantity of hours worked by residents, the goal of our intervention was to increase the quality and efficiency of these hours. Taking a cue from business management literature, our intervention utilized the classic theory of Hackmann and Oldham's Job Characteristics Model, which lays out core job characteristics under which employees will have high motivation, efficiency, and job satisfaction [8]. We focused on improving three mediators of these outcomes: (1) role clarity, (2) skill variety, and 
(3) psychological ownership [8-10]. We instituted a more transparent scheduling system of assigning cases and clinic duties a day ahead (role clarity), based on both staff needs and resident educational requirements (skill variety), and dispersing this list through a service wide email (psychological ownership). We believed that this could improve perceptions of quality of patient care, case allocation, and overall resident education.

\section{Methods}

Surgical residents were allocated by the chief resident to cases and clinic activities a day ahead. The assignment of cases was based on resident year, attending team assignments, and clinic/operating room needs. As these variables change with each day, no algorithms were employed, rather the chief resident would manually assign the cases. A central email was generated specifying the allocations and roles. This was then sent to the students, residents, attendings, and ancillary staff in the Department of General Surgery.

A ten-item questionnaire survey was carried out before the use of the daily resident allocations and results compared to a postinterventional questionnaire at the end of the surgical rotation (4 weeks).

Surgery Quality Improvement Survey

(1) I am a:

[ ] medical student

[ ] PA/NP
[ ] attending
[ ] PGY1
[ ] PGY 2
[ ] PGY3
[ ] PGY4
[ ] PGY 5

(2) How stressed are you at work on a day-to-day basis?

$$
\begin{aligned}
& \text { o 1-not at all } \\
& \text { o 5-very }
\end{aligned}
$$
basis?

(3) How much ancillary staff work do you do on a daily

$$
\begin{aligned}
& \text { o 1-a little } \\
& \text { 5-too much }
\end{aligned}
$$

(4) How well are OR cases distributed among residents?

$$
\begin{aligned}
& \text { 1-poor } \\
& \text { 5-excellent }
\end{aligned}
$$

(5) Do you feel like cases are appropriately/adequately covered?

$$
\begin{aligned}
& \text { o yes } \\
& \text { o no }
\end{aligned}
$$

(6) If not, why?

o case too advanced for me

o my resident is too junior

o not enough residents

o other

(7) How often are you going to clinic?
o $1 \times /$ week
o $2 \times /$ week
o $3 \times /$ week
○ $4 \times /$ week or more
o It's my clinic!

(8) How do you rate the educational value of clinic?

$$
\begin{aligned}
& \text { o 1-poor } \\
& \text { 5-excellent }
\end{aligned}
$$

Please explain:

(9) How well are patients cared for overall on the general surgery/trauma services?

$$
\begin{aligned}
& \text { 1-poorly } \\
& \text { 5-exceptionally }
\end{aligned}
$$

(10) What can be improved about the general surgery/trauma services?

The time period of one month was selected, as this is the typical length of each junior resident rotation. This time period was used in an effort to provide a clearer delineation between pre- and postintervention. The paper questionnaires were distributed to the surgical staff on the General and Trauma/Acute Care Surgery service which included medical students, physician assistants, residents, and surgical attendings at our 627-bed level 1 trauma center. The respondents had been exposed to the "old" method of allocation for at least one month. The study was Institutional Review Boardapproved, and informed consent forms were obtained from each subject.

Questionnaire data were collected using a 5-point Likert scale with results analyzed using Chi-square analysis of categorical data. A percentage of positive response (Likert > 3) was noted for the perception of the outcome measures.

\section{Results}

A total of 28 members of staff completed the preinterventional and postinterventional survey questionnaires. A total of 7 attendings, 16 residents, 4 medical students, and 1 physician assistant completed the surveys. Surgical house staff did not experience a change in the perception of stress at work before or after the use of scheduled OR and clinic assignments (39\% vs. $41 \% ; p=0.9$ ). Daily allocations of residents to the $\mathrm{OR}$ and clinic did not change the perception of inadequate coverage of OR cases (79\% vs. $82 \% ; p=0.76)$ and clinic attendance (68\% vs. $71 \% ; p=0.68)$. The amount 
TABLE 1: Questionnaire results from Chi-square analysis of pre- versus post-intervention response data. Percentage of positive responses (Likert > 3).

\begin{tabular}{lccc}
\hline Question & Preintervention & Postintervention & $p$ value \\
\hline Stress level & $39 \%$ & $41 \%$ & 0.90 \\
Ancillary work & $32 \%$ & $18 \%$ & 0.29 \\
Appropriate case distribution & $54 \%$ & $94 \%$ & $<.001$ \\
Appropriate case coverage & $79 \%$ & $82 \%$ & 0.76 \\
Value of clinic & $39 \%$ & $94 \%$ & $<.001$ \\
Clinic attendance & $68 \%$ & $71 \%$ & 0.68 \\
Quality of patient care & $50 \%$ & $100 \%$ & $<.001$ \\
\hline
\end{tabular}
$n=28$.

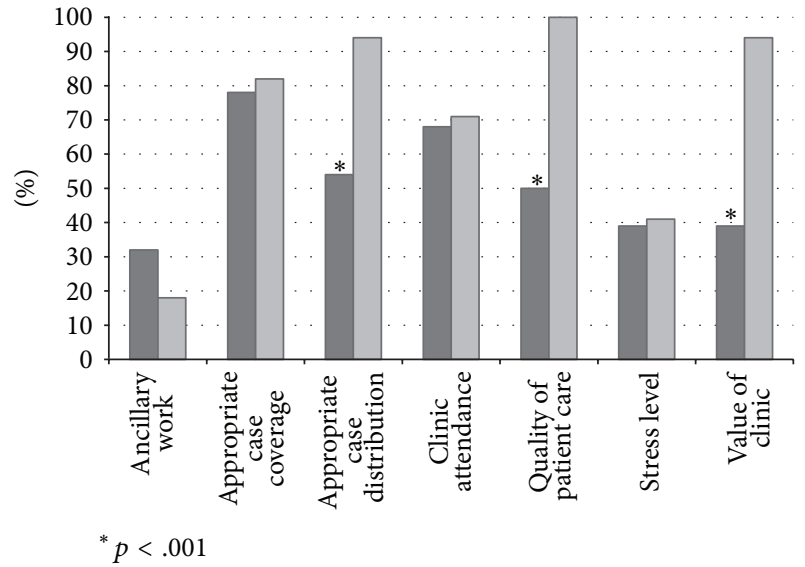

FIGURE 1: Questionnaire results: percentage of positive responses (Likert > 3). Graphical results from Chi-square analysis of preversus postintervention response data. Data marked with an asterisk (*) proved statistically significant with a $p$ value $<0.001$.

of ancillary work performed was decreased (32\% vs. $18 \%$, $p=0.29)$, but this was not statistically significant.

The implementation of a daily resident allocation to the OR and surgical clinics did, however, improve perceptions of educational experience in the clinic (39\% vs. $94 \% ; p<0.05)$, appropriate case distribution (54\% vs. 94\%; $p<0.001$ ), and quality of patient care (50\% vs. $100 \%$; $p<0.05)$. These data are summarized in Table 1 and Figure 1. A subgroup analysis of these data did not prove any statistically significant differences between resident and attending perceptions.

\section{Discussion}

While the 80-hour work week has now been in effect for over 9 years, its effects on patient care and resident training, two of its goal outcomes, have not been clearly delineated in the literature.

Studies supporting work hour reform have demonstrated some beneficial outcomes of the changes, such as decreases in surgical complications and decreases in mortality [1113 ], along with a maintained or increased number of cases performed by graduating surgical residents [14-21]. Investigations with opposing data have found an increase in morbidities or complications following surgical intervention
$[22,23]$, a decrease in the total number of cases logged, or an increase in the percentage of uncovered cases [24-28]. What both groups of studies have demonstrated, however, is that the 80-hour work week has mandated difficult logistical challenges in maintaining continuity of care, appropriate case allocation, and case coverage in surgery programs, which some programs have dealt with successfully and others continue to work toward achieving [7, 28-30].

The findings of our study suggest that these challenges can be overcome by applying a simple but effective managerial model. Utilizing the basis of the Job Characteristics Model, role clarity is defined as "the extent to which required information is communicated and understood" [31]. Skill variety is defined as "a task that requires a person to engage in activities that challenge or stretch his skills and abilities" [8]. And finally, psychological ownership is provided through "coming to intimately know the target, through an investment of self into the target" [10]. These core job characteristics were provided through a transparent and distributed scheduling system: assigning cases and clinic duties a day ahead (role clarity), based on both staff needs and resident educational requirements (skill variety), and dispersing this list through a service wide email (psychological ownership).

Of note, the outcomes of this model are geared towards increasing employee satisfaction and performance. Just as important as measurable education results (i.e., case numbers) is the residents' perception of these factors. It has been shown that the number of cases logged does not consistently correlate with residents' perceived surgical competency upon graduation [32, 33]. By ensuring employee (resident) satisfaction, while also ensuring appropriate case allocation, we believe this intervention helped align residents' expectations of education with actual case volume. These expectations likely explain the discrepancy between attending perception of case distribution and that of the residents in those previous studies.

In addition, we propose that the significant increase in residents' perception of the quality of patient care was positively affected by increasing psychological ownership. By making residents more accountable for scheduled clinic time through the service-wide schedule distribution, residents were afforded more opportunity to follow patients longitudinally and develop a personal connection with patients. Pierce et al. proposed that this increased psychological ownership will result in a more frequent search for job 
enrichment activities (skill and technique advancement) along with enhanced feedback seeking behavior (motivation for increased performance) $[8,10]$.

While our study provided results of a small cohort, we believe this model could be applicable to a wide variety of training programs. These findings highlight the increasing importance of management techniques in the health system, as time afforded for education and experience continues to tighten. Other proposed interventions, such as learning portfolios [34] and leadership training [3], provide the opportunity to further enhance this model and ensure a focus on the quality of training rather than quantity of training.

\section{Conclusion}

The daily allocation of surgical residents to operative cases and clinic activities the day before their duties was demonstrated to improve house staff perceptions of educational experience in the clinic, appropriate case distribution, and quality of patient care.

\section{References}

[1] J. L. Cameron, "William Stewart Halsted: our surgical heritage," Annals of Surgery, vol. 225, no. 5, pp. 445-458, 1997.

[2] “ACGME common program requirements,"2012, http://www .acgme.org/acgmeweb/Portals/0/PFAssets/ProgramRequirements/CPRs2013.pdf.

[3] S. S. Awad, B. Hayley, S. P. Fagan, D. H. Berger, and F. C. Brunicardi, "The impact of a novel resident leadership training curriculum," American Journal of Surgery, vol. 188, no. 5, pp. 481-484, 2004.

[4] C. Freiburg, T. James, T. Ashikaga, J. Moalem, and G. Cherr, "Strategies to accommodate resident work-hour restrictions: impact on surgical education," Journal of Surgical Education, vol. 68, no. 5, pp. 387-392, 2011.

[5] T. E. Day, J. T. Napoli, and P. C. Kuo, "Scheduling the resident 80-hour work week: an operations research algorithm," Current Surgery, vol. 63, no. 2, pp. 136-141, 2006.

[6] S. Topaloglu, "A shift scheduling model for employees with different seniority levels and an application in healthcare," European Journal of Operational Research, vol. 198, no. 3, pp. 943-957, 2009.

[7] J. P. Turner, H. E. Rodriguez, M. S. Daskin, S. Mehrotra, P. Speicher, and D. A. Darosa, "Overcoming obstacles to residentpatient continuity of care," Annals of Surgery, vol. 255, no. 4, pp. 618-622, 2012.

[8] J. R. Hackman, K. R. Brousseau, and J. A. Weiss, "The interaction of task design and group performance strategies in determining group effectiveness," Organizational Behavior and Human Performance, vol. 16, no. 2, pp. 350-365, 1976.

[9] B. G. Whitaker, J. J. Dahling, and P. Levy, "The development of a feedback environment and role clarity model of job performance," Journal of Management, vol. 33, no. 4, pp. 570591, 2007.

[10] J. L. Pierce, I. Jussila, and A. Cummings, "Psychological ownership within the job design context: revision of the job characteristics model," Journal of Organizational Behavior, vol. 30, no. 4, pp. 477-496, 2009.
[11] A. Yaghoubian, G. Saltmarsh, D. K. Rosing, R. J. Lewis, B. E. Stabile, and C. De Virgilio, "Decreased bile duct injury rate during laparoscopic cholecystectomy in the era of the 80-hour resident workweek," Archives of Surgery, vol. 143, no. 9, pp. 847851, 2008.

[12] C. A. Morrison, M. M. Wyatt, and M. M. Carrick, "Impact of the 80 -hour work week on mortality and morbidity in trauma patients: an analysis of the national trauma data bank," Journal of Surgical Research, vol. 154, no. 1, pp. 157-162, 2009.

[13] M. Aynardi, A. G. Miller, F. Orozco, and A. Ong, "Effect of workhour restrictions and resident turnover in orthopedic trauma," Orthopedics, vol. 35, no. 11, pp. 1649-1654, 2012.

[14] M. M. Hutter, K. C. Kellogg, C. M. Ferguson, W. M. Abbott, and A. L. Warshaw, "The impact of the 80-hour resident workweek on surgical residents and attending surgeons," Annals of Surgery, vol. 243, no. 6, pp. 864-871, 2006.

[15] S. T. McElearney, A. R. Saalwachter, T. L. Hedrick et al., "Effect of the 80-hour work week on cases performed by general surgery residents," American Surgeon, vol. 71, no. 7, pp. 552-556, 2005.

[16] K. A. Mendoza and L. D. Britt, "Resident operative experience during the transition to work-hour reform," Archives of Surgery, vol. 140, no. 2, pp. 137-145, 2005.

[17] C. Simien, K. D. Holt, T. H. Richter et al., "Resident operative experience in general surgery, plastic surgery, and urology 5 years after implementation of the ACGME duty hour policy," Annals of Surgery, vol. 252, no. 2, pp. 383-389, 2010.

[18] A. U. Spencer and D. H. Teitelbaum, "Impact of work-hour restrictions on residents' operative volume on a subspecialty surgical service," Journal of the American College of Surgeons, vol. 200, no. 5, pp. 670-676, 2005.

[19] S. Shin, R. Britt, and L. D. Britt, "Effect of the 80-hour work week on resident case coverage: corrected article," Journal of the American College of Surgeons, vol. 207, no. 1, pp. 148-150, 2008.

[20] J. R. Schneider, J. J. Coyle, E. R. Ryan, R. H. Bell Jr., and D. A. DaRosa, "Implementation and evaluation of a new surgical residency model," Journal of the American College of Surgeons, vol. 205, no. 3, pp. 393-404, 2007.

[21] B. S. Izu, R. M. Johnson, P. M. Termuhlen, and A. G. Little, "Effect of the 30-Hour work limit on resident experience and education," Journal of Surgical Education, vol. 64, no. 6, pp. 361364, 2007.

[22] J. A. Browne, C. Cook, S. A. Olson, and M. P. Bolognesi, "Resident duty-hour reform associated with increased morbidity following hip fracture," Journal of Bone and Joint Surgery-Series A, vol. 91, no. 9, pp. 2079-2085, 2009.

[23] T. M. Dumont, A. I. Rughani, P. L. Penar, M. A. Horgan, B. I. Tranmer, and R. P. Jewell, "Increased rate of complications on a neurological surgery service after implementation of the accreditation council for graduate medical education workhour restriction: clinical article," Journal of Neurosurgery, vol. 116, no. 3, pp. 483-486, 2012.

[24] A. M. Carlin, E. Gasevic, and A. D. Shepard, "Effect of the 80hour work week on resident operative experience in general surgery," American Journal of Surgery, vol. 193, no. 3, pp. 326330, 2007.

[25] R. C. Connors, J. R. Doty, D. A. Bull, H. T. May, D. A. Fullerton, and R. C. Robbins, "Effect of work-hour restriction on operative experience in cardiothoracic surgical residency training," Journal of Thoracic and Cardiovascular Surgery, vol. 137, no. 3, pp. 710-713, 2009. 
[26] A. Damadi, A. T. Davis, A. Saxe, and K. Apelgren, "ACGME duty-hour restrictions decrease resident operative volume: a 5Year comparison at an ACGME-accredited university general surgery residency," Journal of Surgical Education, vol. 64, no. 5, pp. 256-259, 2007.

[27] J. C. Kairys, K. McGuire, A. G. Crawford, and C. J. Yeo, "Cumulative operative experience is decreasing during general surgery residency: a worrisome trend for surgical trainees?" Journal of the American College of Surgeons, vol. 206, no. 5, pp. 804-811, 2008.

[28] W. W. Hope, D. Griner, D. Van Vliet, R. P. Menon, C. A. Kotwall, and T. V. Clancy, "Resident case coverage in the era of the 80hour workweek," Journal of Surgical Education, vol. 68, no. 3, pp. 209-212, 2011.

[29] H. Rodriguez, J. P. Turner, P. Speicher, M. S. Daskin, and D. Darosa, "A model for evaluating resident education with a focus on continuity of care and educational quality," Journal of Surgical Education, vol. 67, no. 6, pp. 352-358, 2010.

[30] D. K. Nakayama, W. M. Thompson, J. L. Wynne, M. L. Dalton, A. T. Bozeman, and B. J. Innes, "The effect of ACGME duty hour restrictions on operative continuity of care," American Surgeon, vol. 75, no. 12, pp. 1234-1237, 2009.

[31] J. H. Donnelly and J. M. Ivancevich, "Role clarity and the salesman," Journal of Marketing, vol. 39, no. 1, pp. 71-74, 1975.

[32] A. Safavi, S. Lai, S. Butterworth, M. Hameed, D. Schiller, and E. skarsgard, "Does operative experience during residency correlate with reported competency of recent general surgery graduates?" Canadian Journal of Surgery, vol. 55, no. 4, supplement 2, pp. S171-S177, 2012.

[33] F. Sheikh, R. J. Gray, J. Ferrara, K. Foster, and A. Chapital, "Disparity between actual case volume and the perceptions of case volume needed to train competent general surgeons," Journal of Surgical Education, vol. 67, no. 6, pp. 371-375, 2010.

[34] T. P. Webb and T. R. Merkley, "An evaluation of the success of a surgical resident learning portfolio," Journal of Surgical Education, vol. 69, no. 1, pp. 1-7, 2012. 

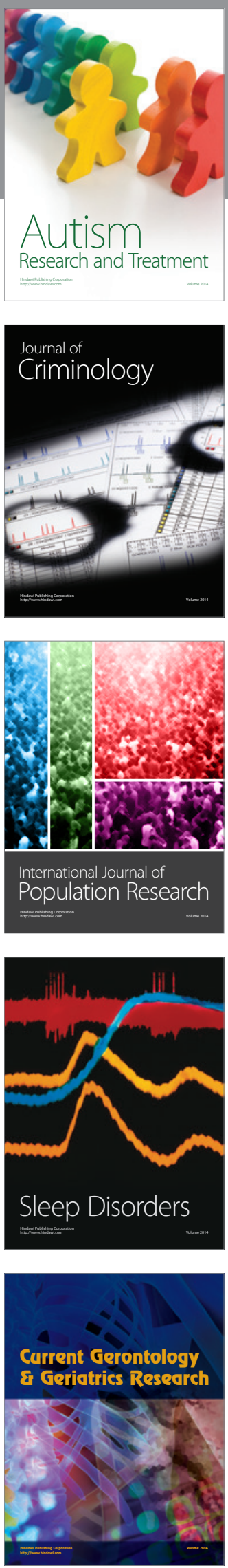
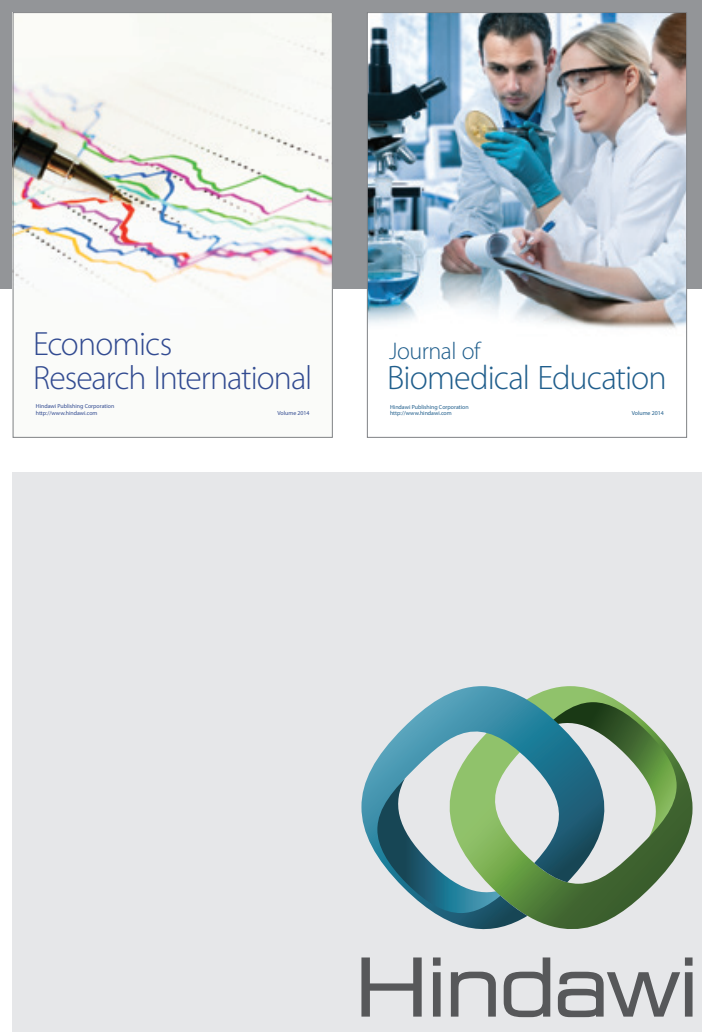

Submit your manuscripts at

http://www.hindawi.com
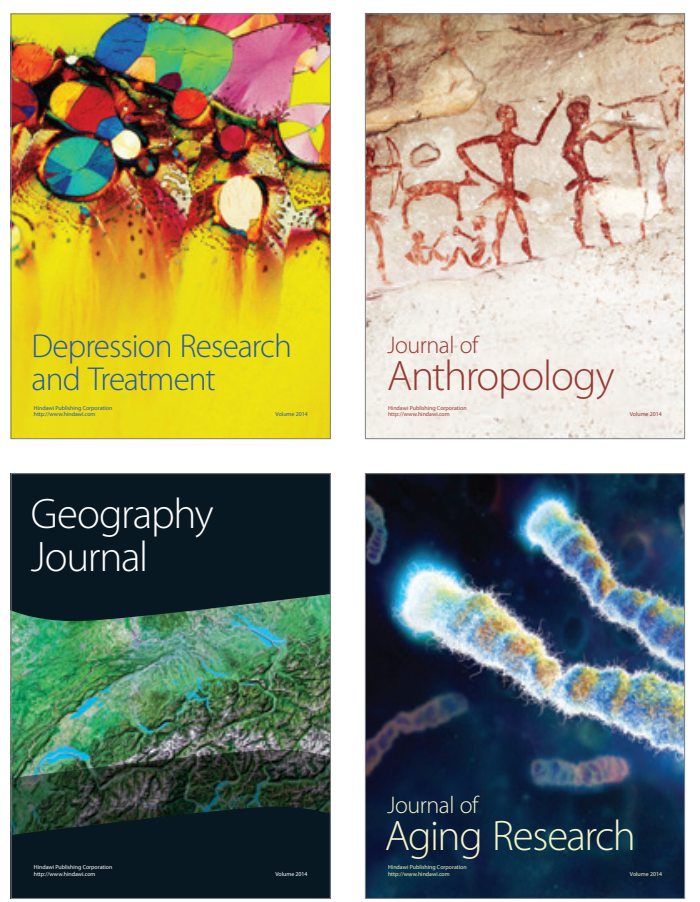
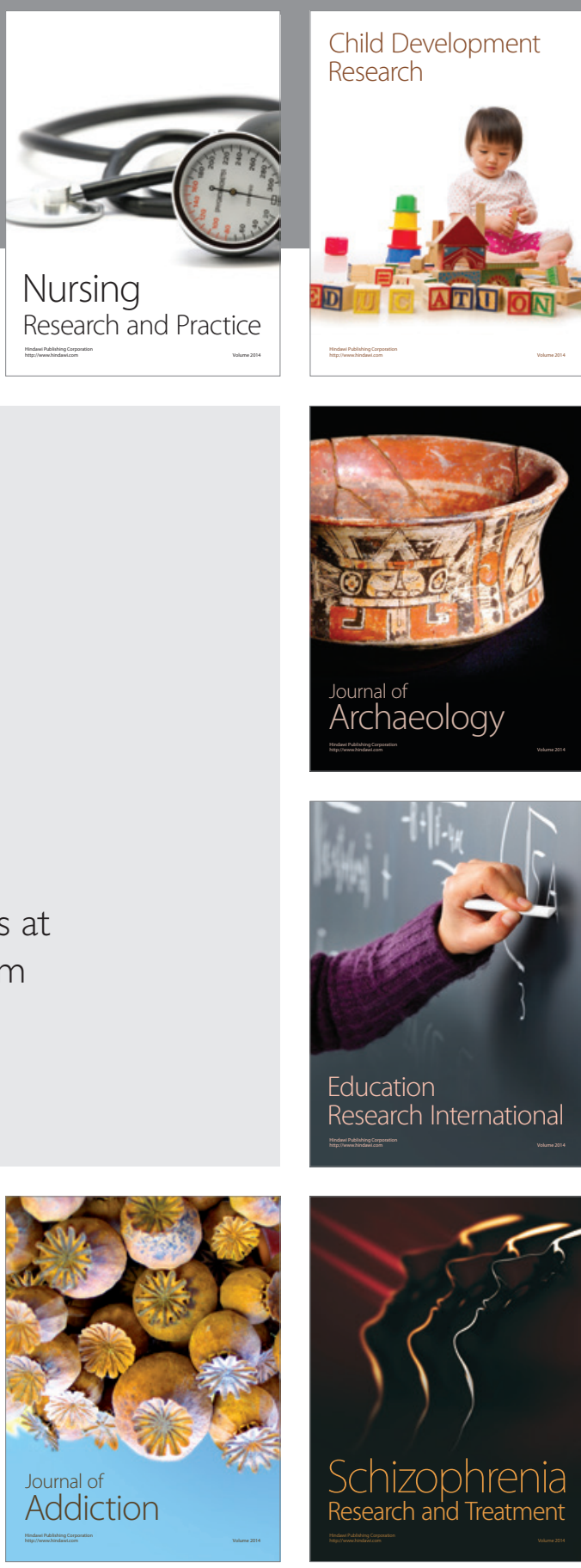

(D)
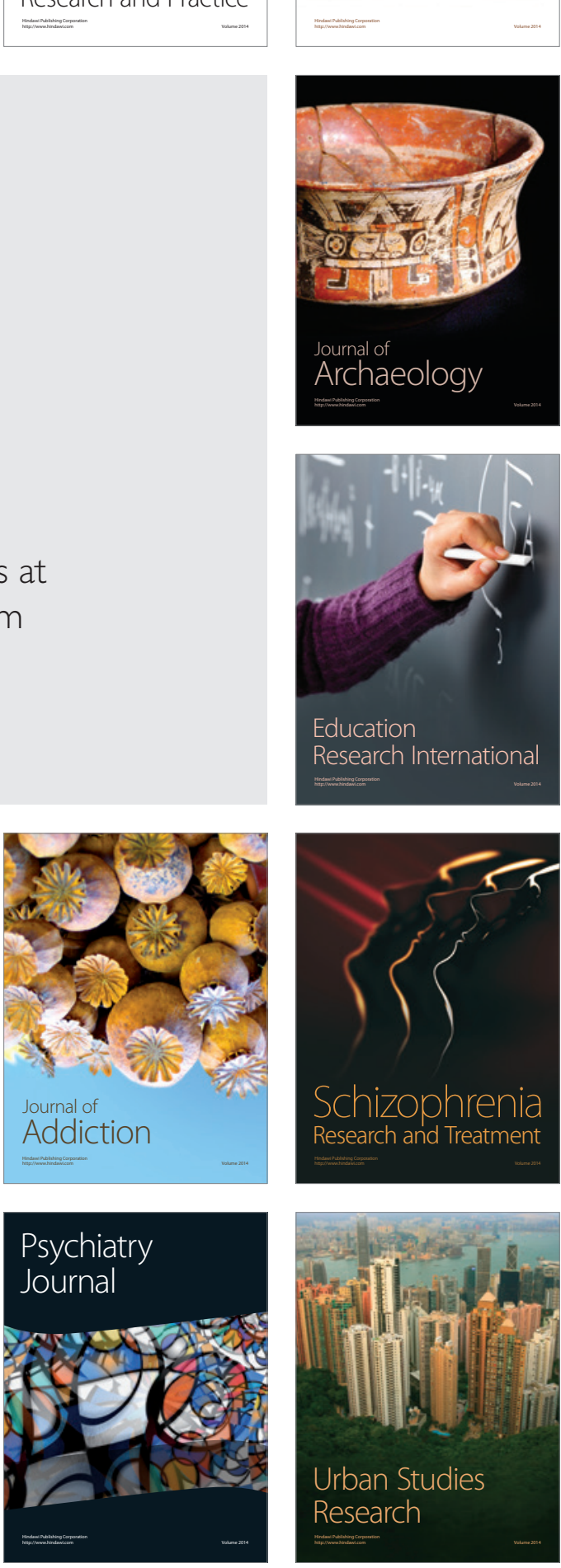